\title{
Pesticide use in Indian cardamom needs change in cultivation practices
}

\author{
M. Murugan*, R. Ravi, A. Anandhi, Sajan Kurien and M. K. Dhanya
}

Indian cardamom farming in the Cardamom Hill Reserves of Kerala has been considered one of the costliest production systems. Questionnaire survey and interviews with cardamom planters between 2008 and 2013 showed that the pesticides used in cardamom production is paradoxical. The reasons are closely associated with the unscrupulous use of pesticides which wiped out the natural enemies of pests and inefficacies of pesticides that led to dose enhancement. Climatic changes along with forest degradation and removal of shade have played a considerable role for increased pesticide consumption. The current perilous situation needs critical thinking to evolve pesticide reduction strategies.

Keywords: Forest degradation, organic cardamom, soil temperature.

INDIAN cardamom (Elettaria cardamomum Maton.) is native to the rain forests of Western Ghats and Central High Lands of Sri Lanka. It is extensively cultivated in Kerala, that too in the degraded tropical Indian Cardamom Hills (ICH). Most tropical mountain ecosystems in the world hold valuable species and considerable biodiversity because of their rich variety of ecological and climatic settings. Some of these mountain forests are at risk because of low management capacity, overuse of resources, and agricultural encroachment and intensification $^{1,2}$. The Intergovernmental Panel on Climate Change (IPCC, 2007) $)^{3}$ reported that at least $12-36 \%$ of the earth's land surface including mountains will experience new climates. Even without climate change, pest intensity will increase, which can significantly change pesticide usage and sustainability of precious agro-ecosystems. Past cultivars of cardamom used to grow and yield well with minimum manure and chemical inputs under good shade. Since 1990, introduction of high yielding varieties which have a capacity to perform well under more open forest system, along with adaptability for higher inputs of application of chemical fertilizers and manures paved the way for a phenomenal increase in cardamom yield. A questionnaire survey and interviews conducted between 2008 and 2013 in the Cardamom Hills revealed a five-fold increase in cardamom yield productivity. Pesticide con-

M. Murugan and M. K. Dhanya are in the Cardamom Research Station, Kerala Agricultural University, Pampadumpara 685 553, India; R. Ravi is in the Materials Engineering, Indian Institute of Science, Bengaluru 560 012, India; A. Anandhi is in the Biological Systems Engineering Program, College of Agriculture and Food Sciences, Florida Agricultural and Mechanical University, Tallahassee, Florida 32307, USA and Sajan Kurien is in the College of Horticulture, Kerala Agricultural University, Thrissur 680 553, India.

*For correspondence. (e-mail: muthupeyan@gmail.com) sumption of the crop also increased several times in the last 50 years $^{2}$. Most of the cultivation of small cardamom in southern India involves high use of chemical pesticides ( $>15$ rounds of pesticide application per season) and 3-6 rounds of application of fertilizers ${ }^{2}$. By contrast, the world's highest producer, Guatemala, consumes very low quantities of chemical pesticides in its cardamom production (Western Mountains) owing to low pest pressure. Therefore, the Indian cardamom industry is pushed by competition to achieve yield maximization which is the only viable option for planters to maintain their economic sustainability. Chemical pesticide application is inevitable at all levels of cardamom farming. Pathways of applied pesticides can be very complicated in this perennial mixed agroforestry system. Continued and concerted research and analysis is needed to avoid illogical and unwanted application of pesticides to address both agronomic and environmental sustainability of the precious cardamom ecosystem. More than $80 \%$ of India's small cardamom production comes from Kerala where two distinct ethnic groups are involved in the cultivation of this crop for the last several decades. Kerala wanted to go into organic farming from 2016, while for various reasons Tamil Nadu preferred to continue to practise inorganic farming at least for the foreseeable future. This meant that toxic pesticides will be very much available in the nearby Theni district of Tamil Nadu close to the cardamom hotspots in Kerala. Therefore, imposing restrictions on pesticides and its use in Kerala will have little impact on the fragile cardamom ecosystem. Groups of cardamom planters in many high productive hotspots in Cardamom Hill Reserve (CHR) area have societies through which they sell toxic pesticides to fellow planters, and in this way, all planters who are diehard users of chemicals maximize their use. More than $95 \%$ of the total area 
under cardamom cultivation in Kerala grows a variety called 'green gold', which is highly susceptible to multiple stresses. This variety is a heavy consumer of surface soil nutrients; therefore, external application of fertilizers and manures is unavoidable to maintain higher yields. Considering the volatile market, most cardamom planters are not ready to lose or forego even $500 \mathrm{~g}$ of their cardamom produce. Cardamom pest control has major challenges because of the absence of sufficient population of natural enemies of pests in the Cardamom Hills ecosystem and also complexities in the use of biological control methods and products. Experiments in research stations on many organic cardamom treatments resulted only in one third produce relative to the average yield achieved by planters during the second and third year after planting. Even the best organic treatment plots had registered a maximum yield of $750 \mathrm{~kg} / \mathrm{ha}$. This warrants further meticulous experimentation and validation to enhance yield levels by organic means. Consequently the use of chemicals that increase crop production and protection is inevitable in cardamom cultivation industry. Therefore, practically, no field/planter has fully adopted organic production of cardamom. Critical thinking and analysis to develop a complete organic production protocol are still required. As cardamom farming continues to get modernized, concerns increase about pesticide loads in the valuable rainy agroecosystem in which cardamom is grown. Protecting the soil and water quality as well as profitable cardamom farming in CHR could be a major future challenge.

The ICH $\left(9^{\circ} 15^{\prime} \mathrm{N}-10^{\circ} \mathrm{N}, 76^{\circ} 45^{\prime} \mathrm{E}-77^{\circ} 25^{\prime} \mathrm{E}\right)$ is located at an elevation ranging from 700 to $1300 \mathrm{~m}$ amsl and the northern edge of the $\mathrm{ICH}$ abuts the high ranges (HR), where the highest-altitude tea plantations in the world are located in the state of Tamil Nadu. A survey encompassing the entire CHR (1050 sq. km) was conducted during 2008-2013, and data collected through interview of select number of planters $(n=103)$ on key socioeconomic aspects of pesticide used in cardamom cultivation. A total of 70 soil samples (from cardamom rhizosphere and nonrhizosphere as well as least disturbed forest soils) were collected and analysed for various biological properties that were pertinent for our research. Climate data, including soil temperature values were collected from the agrometeorological observatory attached to the Cardamom Research Station (CRS) located at Pampadumpara (the oldest representative climate station for the $\mathrm{ICH}$ region). Observations on pest incidence levels were recorded in the fields nearest to the observatory, approximately within 500-1000 $\mathrm{m}$ distance.

The seasons can be defined as conventional (fixed) or floating. In a fixed season, the starting dates and length of seasons remain the same for every year. In a floating season, the date of onset and duration of each season is allowed to change from year to year. Studies have shown that floating seasons reflect the natural seasons in the climate data better than fixed seasons, especially under changing climate conditions $\mathrm{s}^{4,5}$. Therefore, this study used floating seasons to effectively capture seasonal changes. Weather classification methods are used in this study to define the length of floating meteorological season, which are linked by grouping the monthly datasets of surface climate variables into a finite number of discrete weather types, or seasons. Rainfall and relative humidity were used to define wet and dry seasons, whereas temperature was used to define warm and cold seasons. This study used hybrid approach of $K$-mean clustering, because it had the advantage of both subjective and objective approaches. Hybrid techniques combine elements of empirical and automated procedures for grouping the seasons, thereby avoiding time delay and enabling the production of easily reproducible and interpretable results. For more details on the methodology, please see Anandhi ${ }^{5}$. The brief steps involved in stratification of seasons are as follows:

1. Selection of meteorological variable of interest for stratification.

2. Standardization of meteorological variable to reduce systemic bias (if any) in the mean and variance of the variable. This step typically involves subtraction of the mean and division by the standard deviation of the predictor for the period.

3. Formation of feature vectors using standardized meteorological variables for each month. The feature vectors form input to the $K$-means clustering algorithm, and the season is its output.

4. Partitioning of feature vectors into clusters that depict seasons using $K$-mean clustering. In this analysis, each feature vector of the data (representing a month) is treated as an object with a location in space. The feature vectors are partitioned into clusters such that the feature vectors within each cluster are as close to each other as possible in space and are as far as possible in space from the feature vectors in other clusters.

5. The distance between feature vectors in space is estimated using an Euclidian measure. Subsequently, each feature vector (representing a month) is assigned a label that denotes the cluster (season) to which it belongs.

6. Formation of feature vectors using principal components (PCs). The PCs for each month form a feature vector. The feature vectors form the input to the $K$-mean clustering algorithm, and the seasons are its output.

7. From the seasons, depending on the months falling in each season, the length of the season in months is determined.

8. For a season, estimate the average season length and the uncertainty limits.

The precipitation pattern observed in CHR showed increased break periods (wet and dry spell rain fall patterns) (Figure 1) between 2000 and 2008, particularly in the months of June, July and August. Rainfall in September 
Table 1. Statistics on the number of pesticide sprays and percentage share of pesticides used against cardamom pests during the study period $(n=103)$

\begin{tabular}{lccccc}
\hline Statistics & Thrips & Borers & Root grubs & Whiteflies & Nematodes \\
\hline Mean & 4.0 & 5.2 & 1.2 & 1.3 & 1.1 \\
Range & $1-12$ & $1-12$ & $1-3$ & $1-3$ & $1-3$ \\
SD & 1.6 & 2.1 & 0.4 & 0.5 & 0.4 \\
Percentage share of pesticides & 12.4 & 19.5 & 6.0 & 3.8 & 4.9 \\
\hline
\end{tabular}
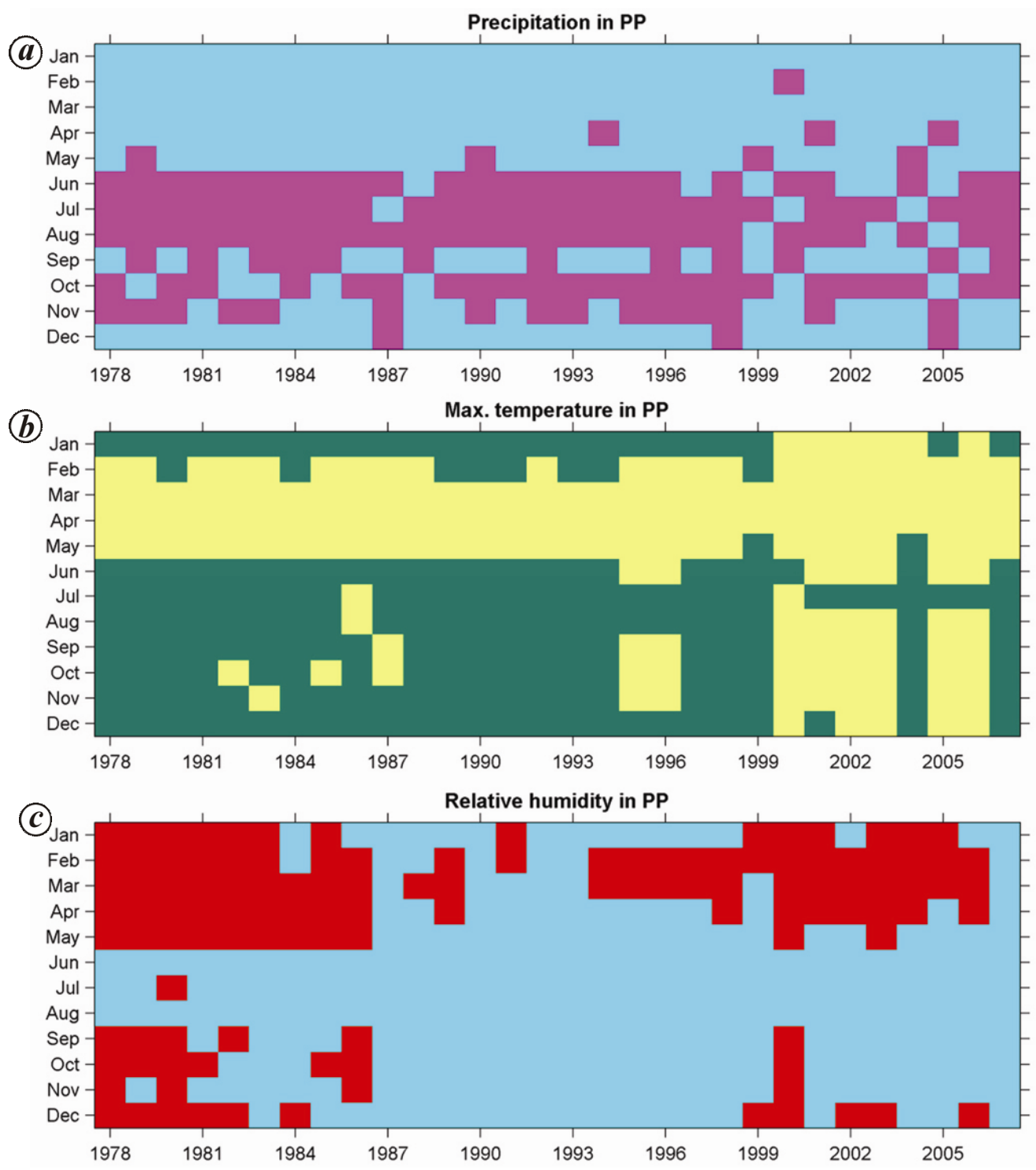

Figure 1. Cluster analysis for Pampadumpara (PP). a, The rainy season is shown in pink ( $\square$ ), and the dry season is represented in blue $(\square)$. $\boldsymbol{b}$, The warm season is shown in yellow $(\square)$, and the cool season is represented in green $(\square)$, The dry season is shown in red $(\square)$ and the wet season is represented blue $(\square)$.

followed by November varied much more than in any other monsoon months. Rainfall in summer months since 1999 has progressively increased, particularly in April and May. An inconsistent rainfall pattern was observed for November since 1981 and significant rainfall was received in this month in only a few years. The pattern of rainfall for January and December did not vary much during the study period. Erratic rainfall across all seasons occurred and favoured cardamom pest development, predominantly the shoot and capsule borers, thrips, root grubs and whiteflies. Decreased precipitation levels in July-September months have increased the population 
levels of major pests, particularly thrips and capsule borers, sufficient enough to inflict serious damage to the developing capsules. Consequently more sprayings had to be done to manage the pests (Table 1). Since capsule borers are cryptic in nature, their chances to escape pesticide exposure are high. Therefore repeated application of pesticides is inevitable. The population of thrips never dropped, even during intense rainfall. More sprayings had to be done during the 2013 season because of this. All planters who were interviewed expressed that pesticide spray focussing on control of thrips always resulted in better cardamom quality which fetched higher price in the auction centres. As a result, planters did not hesitate to give frequent pesticide spray. An early start and prolonged summer along with increased frequency of break periods during monsoon months provided an encouraging environment for whiteflies, management of which was challenging. Continuous use of synthetic pyrethroids and combination products had led to population build-up of sucking (whiteflies) and lacerating type (thrips) pests, which required extra pesticides once again to manage these pests. For this reason the population of major pests remained high throughout the season, and most planters had to use combination sprays many times, mostly quinalphos and chlorpyrifos and sometimes other chemicals too such as pyrethroids (cypermethrin), triazophos and imidachloprid. Summer rainfall, higher mean minimum temperatures, and higher relative humidity had significant positive effects on continuous flowering and yield; and this favoured planters to go for increased use of pesticides to avoid harvesting of poor quality cardamom capsules (itched capsules).

Increased atmospheric temperature trends in CHR were clear and significant on monthly to decadal scale and were asymmetric in that the mean minimum temperature increased more quickly than the mean maximum temperature. Such an increase in temperature caused the diurnal temperature range (DTR) to decrease. DTR is critical for growth and development of plants as well as insect species (Figure 1). All months except for July between 1999 and 2007, showed warming tendency. The year 2004 was the coolest in the first decade of the century, followed by 2007. The observed weather data at the station showed that the atmosphere was cooler up to 2000 except in summer months (February through May). Except for a few years in the 1980s, the 1980s and 1990s were the cooler decades. During this period, the number of pesticide sprays was much lower ( 8 to 10$)^{2}$ compared to the present decade. Climate warming (since 2000) has increased the population of thrips, borers, whiteflies and mites in plots that were close to the observatory. Along with higher atmospheric air temperature, the elevated surface soil temperature (Figure 1) also helped increase the population of root-feeding soil insect pests such as root grubs, nematodes, etc. Evidence showed that the number of drenchings of soil with insecticides and nema- ticides to manage the soil insect pests has significantly increased (3-4 drenchings) during the past 15 years. Multiplication and spreading of soil dwelling insect pests attacking cardamom is very slow and hence they are very much localized and confined to a specific place. Although drenching of pesticides to control these pests is being taken up to cover the entire field including pest-free soil areas, application of soil pesticides in non-infested soil areas is inappropriate and therefore avoidable.

From mid-1980s through late 1990s, the atmospheric environment was mostly cooler and had high relative humidity ( $\mathrm{RH})$ (Figure 1). The increase in atmospheric $\mathrm{RH}$ resulted in higher disease intensity even during summer months, ensuing greater demand for fungicides (6-7 rounds in 2013). Around 2004, dry condition (lower RH) prevailed during summer and December was the coldest month. Sunshine hours rose by nearly $1 \mathrm{~h}$ from 1990 through 2004, and the difference was greater from 2004 through 2013. Soil temperatures at 5 and $10 \mathrm{~cm}$ depths increased steadily since 1990 (Figure 2). Shade lopping (Figure 3) and surface air warming had a positive influence on surface soil temperature. Favourable surface soil temperature coupled with optimum soil moisture had a

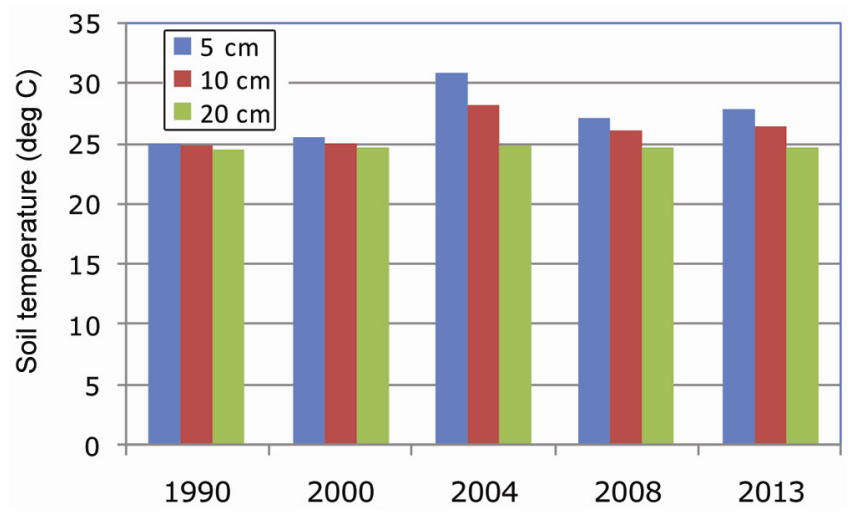

Figure 2. Soil temperature variability recorded at the observatory (cumulative annual average, in ${ }^{\circ} \mathrm{C}$ ) for 5 -, 10- and 20 -cm depths.

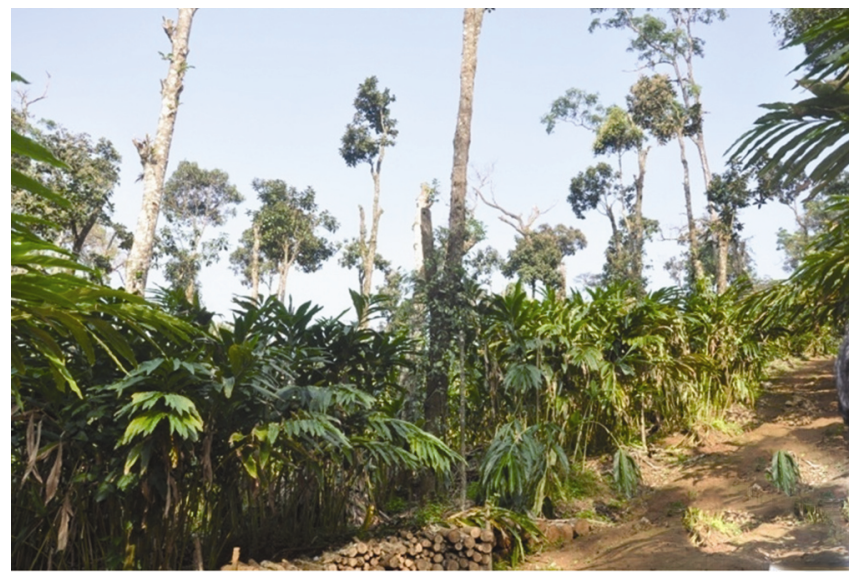

Figure 3. Level of shade removal in a yielding plantation with minimum tree stand. 
Table 2. Soil fauna diversity and biochemical properties observed in CHR soils

\begin{tabular}{lccc}
\hline Organism & Rhizosphere soil & Bulk soil & $\begin{array}{c}\text { Least disturbed } \\
\text { soil (CHR) }\end{array}$ \\
\hline Bacteria $\left(\times 10^{7} \mathrm{CFU} / \mathrm{g}\right.$ soil) & 48.25 & 40.40 & 35.80 \\
Fungi $\left(\times 10^{4} \mathrm{CFU} / \mathrm{g}\right.$ soil) & 22.90 & 9.95 & 5.40 \\
Actinomycetes $\left(\times 10^{5} \mathrm{CFU} / \mathrm{g}\right.$ soil) & 4.80 & 8.15 & 6.85 \\
Diazotrophs $\left(\times 10^{4} \mathrm{CFU} / \mathrm{g}\right.$ soil) & 12.75 & 8.85 & 13.45 \\
$\mathrm{CO}_{2}$ evolution $(\mathrm{mg} / 100 \mathrm{~g}$ soil/h) & 0.045 & 0.039 & 0.042 \\
Dehydrogenase $(\mu \mathrm{g}$ TPF/g/h) & 0.09 & 0.06 & 0.04 \\
& Average & Moderate & $75-85$ \\
Root cation exchange capacity & 62.53 (range 39.42-102.58) & $65-75$ & \\
$\quad\left(\right.$ meq $\left.100 \mathrm{~g}^{-1} ; n=70\right)$ & & & \\
\hline
\end{tabular}

Table 3. Quantity and type of pesticides used against cardamom pests in a year $(n=103)$

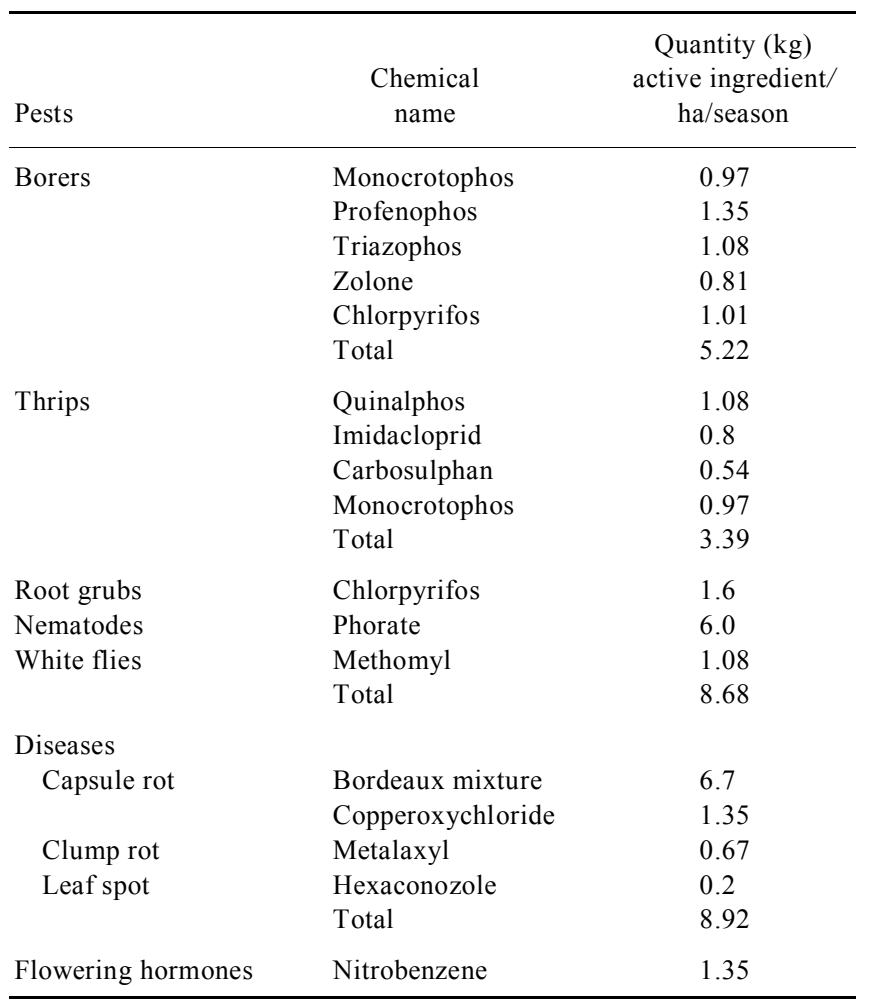

positive influence on soil insect pests (root grubs and plant parasitic nematodes) ${ }^{6}$. More shade removal in cardamom plantations on a regular basis also contributed to forest micro-climatic change, leading to higher pest infestation and pesticide use. Mites and whiteflies are directly linked to more openness and with severe pruning of shade trees, the incidences of these pests increased among plantations studied (Figure 3). It is known that cardamom planters open up forest canopy and prune them to allow more sunlight to fall on the cardamom canopy and soil surface to increase yield and suppress diseases. The practice of shade removal has invited an inevitable evil which means it has altered the microclimate of the cardamom forest and invited more pests to attack cardamom. Shade lopping in cardamom plantations, instead of suppressing the diseases, has increased the number of insect pests attacking cardamom. This has led to more and more use of pesticides to contain the pest problems. The meaning and purpose of shade lopping was routed. We have observed cardamom plantations in Tamil Nadu (Mehgamalai) using minimal shade lopping to maintain the forest microclimate, which had kept the pest levels under control. Steady and higher yield realized by cardamom planters in recent years was attributed to continuous higher application of manures and fertilizers in the nutrient-poor soils of the CHR. Such a high application always resulted in higher concentrations of plant nutrients in tissues and plant parts, which made cardamom clumps more susceptible to pests ${ }^{7}$. Table 2 shows details about the biological properties of cardamom soils including the root cation exchange capacity (RCEC) of the most popular variety in use, 'green gold'. Since the RCEC of the variety is very high, it absorbs higher quantities of essential plant nutrients that are present in bio-available form in the rhizosphere soil. That is why the robust ruling variety is succulent and susceptible to many pests. In cardamom rhizosphere soils, the highest colony-forming units (CFU) was reported for bacteria and fungi species, whereas it was lowest for Actinomycetes. Such soils can cause diseases to cardamom when conducive environments occurred. Ultimately, many practices in cardamom farming with an intention to increase cardamom yield, along with changing climatic conditions, paved way for excess consumption of pesticides. Surface soil samples collected from many cardamom hotspot areas had residues of major pesticides in higher quantities ${ }^{8}$.

Cardamom farming in $\mathrm{ICH}$ in recent years has consumed more insecticides than fungicides, nematicides or flowering hormones. Capsule borers (Conogethes punctiferalis Guenee) consumed more pesticides $(3.44 \mathrm{~kg}$ ai/ha/season) than thrips (Sciothrips cardamom Ramk.) (2.85 kg ai/ha/season) and root grubs (Basilepta fulvicornis Jacoby) (1.6 kg ai/ha/season) (Table 3). Most of the pesticides $(90 \%)$ used to manage these major insect pests were organophosphates except Imidacloprid. In terms of quantity, foliar and soil insect pests respectively, 
consumed 6.29 and $6.6 \mathrm{~kg}$ ai/ha/season (Table 3). From 2012 onwards the most toxic red and yellow labelled organophosphate pesticides were restricted in Kerala and, therefore, they are now not in use. Interestingly, the amount of pesticides used in cardamom has not changed much. As far as average number of rounds of pesticide administration in a season is concerned, maximum spray rounds goes to borers (5.2) followed by thrips (4.0), whiteflies (Kanakarajiella cardamomi David and Subramaniam) (1.3), root grubs (1.2) and nematodes (root knot nematodes) (1.1) (Table 1). Examination of the percentage share of pesticides used for each pest shows that it was maximum for borers (19.5) and minimum for whiteflies (3.8), and the contribution for thrips was in the order of $12.4 \%$. Root grubs and plant parasitic nematodes respectively, used $6.0 \%$ and $4.9 \%$ of the total pesticides (Table 1). The severity of damage by pests in cardamom plantations varied across climatic conditions and shade levels as well as intensification of inputs. Higher quantities of toxic flowering hormone (4 to 5 applications of nitrobenzene) and soil insecticides can lead to serious health implications. Many planters have expressed mild health problems with spraying of triazophos and lambdacyhalothrin. Planters opined that they rely on chemicals for pest management because suitable safer alternatives are not available. Considering the fundamental principles that govern the functioning of all ecosystems (including agroecosystems) they depend on the composition and diversity as well as the physical condition they experience, particularly the disturbance regimes. Therefore, greater stability of cardamom yields without compromise on the future environmental quality can be attained only by maintaining a mixture of appropriately chosen genotypes and varieties at farm and plantation levels, and also by adopting truly integrated crop and pest management strategies including ecological pest management methods systematically.
1. Reyes, T., Luukkanen, O. and Quiroz, R., Small cardamom-precious for people, harmful for mountain forests. Mountain Res. Dev., 2006, 26(2), 131-137.

2. Murugan, M., Shetty, P. K., Ravi, R., Alappan, S. and Murigendra, B., Environmental impacts of intensive cardamom (small) cultivation in Indian cardamom hills: the need for sustainable and efficient practices. Recent Res. Sci. Tech., 2011, 3(2), 9-15.

3. IPCC, 2007: Climate Change: The Physical Science Basis. Contribution of Working Group I to the Fourth Assessment Report of the Intergovernmental Panel on Climate Change (eds Solomon, S. et al.), Cambridge University Press, Cambridge, New York, 2007, p. 996.

4. Anandhi, A., Srinivas, V. V., Nanjundiah, R. S. and Kumar, D. N., Downscaling precipitation to River Basin in India for IPCC SRES scenarios using support vector machine. Int. J. Clim., 2008, 28, 401420 .

5. Anandhi, A., Assessing impact of climate change on season length in Karnataka for IPCC SRES scenarios. J. Earth Sys. Sci., 2010, 119, 447-460.

6. Murugan, M., Shetty, P. K., Mukund, V. and Panigraghy, B., Soil and surface air warming in cardamom ecosystem in southern Western Ghats, Kerala, India. Int. J. Agric. Rural Dev., 2009, 11(2), 5264.

7. Murugan, M., Bijoy, K. P., Shetty, P. K., Subbiah, A. and Ravi, R., Effect of heavy metal and nutrient uptake by soils in Indian Cardamom Hills. J. Soil Sci. Environ. Manag., 2012, 3(8), 196-206.

8. Murugan, M., Shetty, P. K., George, T., Ravi, R. and Alappan, S., Pesticide use in Indian cardamom hills-patterns, factors and intensity. Int. J. Social Ecol. Sust. Dev., 2014, 5(3), 65-80.

ACKNOWLEDGEMENTS. M.M. thanks Director, NIAS, Bengaluru, for facilities and financial assistance. This paper is the outcome of a part of the work done for his PhD programme. The authors thank Arun K. Shanker, CRIDA-ICAR, Hyderabad, for editing and critical comments on the paper.

Received 27 July 2015; revised accepted 9 May 2017

doi: $10.18520 / \mathrm{cs} / \mathrm{v} 113 / \mathrm{i06} / 1058-1063$ 